\title{
The International Multimodal Transport of Hazardous Goods and Waste
}

\author{
Giancarlo Carosso, Cesare Luceri and Pierpaolo Oreste
}

Department of Environment Land and Infrastructure Engineering, Faculty of Engineering, Politecnico di Torino (Italy), Corso Duca degli Abruzzi 24, 10129, Torino

Received 2012-06-13, Revised 2012-07-04; Accepted 2012-07-10

\begin{abstract}
The international multimodal transport of hazardous goods and waste is a sector of remarkable economic importance. This transport activity is connected to several productive sectors and it can have considerable repercussions on the environment and health as well as on the safety of the workers and third parties that study in the same field. A certain part of the transport of hazardous goods and waste is managed by organized criminals who can obtain enormous savings by neglecting the measures necessary to protect the environment and safety. The legitimate economy is thus damaged and, above all, the efforts the International Community has made since the fifties-sixties, concerning the regulation of the complex aspects of this activity, are undermined. Two distinct judicial models exist at an international level concerning hazardous waste and goods: "transboundary movement" and "international transport". The purpose of these models is to regulate a phenomenon which, although very complex and articulated, requires a homogeneous view. The international multimodal transport judicial model is here examined in 3 subsequent stages: (1) the general aspects and the details along the entire chain, starting from the loading operations, then going on to the transport itself and ending up with the unloading at its final destination; (2) the controls on the respect of international legislation on this topic; (3) a study case is conducted pertaining to the extensive PCB category which, from a judicial point of view, in certain cases can be considered hazardous goods and in other cases hazardous waste. The aim of the study is to supply decision makers with indications that can be used to improve the efficacy and the effectiveness of the regulations at a UN level and of the cascading particular agreements for the various means of transport. The international multimodal transport judicial model suffers from the uncertainties that were already encountered for the transborder movement model, with particular reference to the lack of a unique interpretation of what is waste and what are goods at an international, regional and national level. This difficulty, which was already present in the first model, has negative repercussions on the second one and diminishes the efficacy and effectiveness of the interventions put into place to solve the real problems of multimodal transport which, if considered separately, would be valid. Even the controls, which are basically objectively complex and costly, come up against difficulties right from the beginning. Finally, the study case of PCBs also shows that the lack of a solution to the fundamental problem reduces the various operations inherent to transport to almost just a heavy bureaucratic practice, which suffers from practical implications that make it difficult to reach the objectives of protecting the environment and safety that the model has established. The attention of decision makers should be concentrated on two fundamental aspects. The first concerns the fundamental theme of the difference between goods and waste which, being unresolved, weakens many parts of the two models and results in the amplification of the problems on the second model. The second aspect regards the controls that should be conducted. The improvement of the technicaljudicial model requires the combined study of experts, from both the judicial and technical fields.
\end{abstract}

Keywords: Transport of Dangerous Goods (TGD), UN Economic Commission for Europe (UNECE), Economic Commissions for Africa (ECA), Provisional International Civil Aviation Organization (PICAO) 


\section{INTRODUCTION}

\subsection{The Problem}

The international transport of hazardous goods and waste is connected to the various modes of transport that are used (by road, rail, sea, inland navigation and by air), with the problems connected to the intrinsic safety of the transport means and therefore of the material that is transported, the safety of the workers and of the third parties that use the means of transport. Problems related to safety and the environment, as well as economic consequences, can emerge during any stage of international transport, from the loading of the goods or wastes to the intermediate stopovers, from the possible stops to the final unloading of the goods or waste. These complex international transport operations, whether single or multimodal and whether related to hazardous goods or hazardous waste, are regulated at an international level by the UN, from a general point of view and, as far as the five means of transport are concerned, by the same number of international agreements. In these international agreements, the reference to hazardous goods is explicit; however, the extension of the rules pertaining to the transport of hazardous goods to the transport of hazardous waste is less explicit (and is even missing in the documents), if above a determined quantity. Organized crime has in part become involved in the international transport field, in dishonest competition with the legal transport system and in particular organized crime, which violates international regulations concerning the transport of hazardous goods and waste, has taken over a part of the market. Resort to illegal forms of transport of hazardous goods leads to large savings, to the detriment of all those preventive and protective measures that are necessary to guarantee the safety and health of the workers and of the third parties that are involved and to guarantee the protection of the environment and of the ecosystem involved, according to the mode of transport. In this way, the normally high costs of the various preventive and protective measures become the responsibility of the public in general, costs which soar when, because these measures have been neglected or put into practice in an unsuitable way, accidents occur at study, or road, railway or sea accidents occur with the release of hazardous substances or mixtures (as products or as waste) that contaminate the ground, the subsoil, the groundwater or the marine ecosystem.

\subsection{Approach to the Problem}

The substantial failure of the efforts made by the International Community to regulate international transport is surely due to economic factors (Fiore et al.,
2008; 2012; Oreste and Castellano, 2012; Blengini et al., 2012; Sumit, 2009; Mathur and Siddharth, 2009), but experts in the sector (Carosso, 2010) have already underlined, although only with reference to the old international road transport regulations of hazardous waste, the intricacy of these regulations and the nature of their uncertain connection with other provisions on waste. An integrated arrangement of the international regulations on all means of transport and with reference not only to hazardous waste, but also to hazardous goods, has been considered essential. As mentioned in Carosso (2001a), in a study connected to this problem, the transboundary movement of hazardous goods is dealt with by two unconnected sets of regulations: from the technical point of view, the problem is dealt with through a single set of extremely complex articulated regulations that are full of interrelations with other questions, but from the judicial point of view, at an international level, the themes pertaining to the transboundary movement of hazardous wastes are dealt with in two unconnected sets of regulations. In the aforementioned study, it was shown how the uncertainty concerning the starting point, that is, on the definition of waste and on the weak difference between what can be considered goods/product and waste, can be considered an extremely weak point of the regulations pertaining to the transboundary movement of waste. In this study, we capitalize on this result and go on to examine the most important aspects in more detail (loading and unloading; classification, packaging, labeling of the goods and wastes for transport purposes; safety of the workers and third parties as well as management of possible emergencies) that concern the entire multimodal hazardous goods and waste transport chain. As in the companion study, attention is also focused on controls and, for an easier visualization of the problem, the reader can refer to the Multimodal Dangerous Goods Form that is found in chapter 5.4.4 of Part 5; this form is the same for all the particular international regulations concerning the various modes of transport (by sea, railway, road, internal navigable routes).

The category of materials consisting of, containing or contaminated with PCBs, PCTs or PBBs are again considered in this study, as a practical case, to examine from the transport point of view. These substances are found in a number of physical forms, including: capacitors, circuit breakers, electrical cables, electric motors, electromagnets, heat transfer equipment, hydraulic equipment, switches, transformers, vacuum pumps, voltage regulators. Different cases can be observed of a category that can, from a judicial point of view, have the legal description of being considered either a product or waste. 


\section{MATERIALS AND METHODS}

\subsection{Globally Harmonized System of Classification and Labeling of Chemicals (GHS)}

Chemicals directly or indirectly affect everyday life and are essential to food, health and lifestyle. The widespread use of chemicals has resulted in the development of sector specific regulations which can be different from sector to sector, such as in transport, production, workplaces, agriculture, trade and consumer products. The sound management of chemicals should include systems through which chemical hazards are identified and communicated to all those who are potentially exposed. These groups include workers, consumers, emergency responders and the public. The "Globally Harmonized System of Classification and Labelling of Chemicals (GHS)", addresses the classification of chemicals according to the types of hazard and proposes harmonized hazard communication elements, including packagings, labels and safety data sheets, SDSs, (www.unece.org). The first edition of the GHS, which was intended to serve as the initial basis for the global implementation of the system, was approved by the Committee of Experts at its first session (11-13 December 2002) and published in 2003. Since then, the GHS has been updated, revised and improved every two years, as needs arise and experience has been gained in its implementation. The fourth revised edition of the GHS (GHS Rev.4) takes account of the amendments adopted by the Committee of Experts on occasion of its fifth session (10 December 2010) (UN, 2009a).

\subsection{The UN Model Regulations}

The UN Recommendations on the Transport of Dangerous Goods-Model Regulations have been developed by the United Nations Economic and Social Council's (UN ECOSOC) Committee of Experts on the Transport of Dangerous Goods (TGD) in the light of technical progress, the advent of new substances and materials, the exigencies of modern transport systems and, above all, the requirement to ensure the safety of people, property and the environment. They are addressed to governments and international organizations concerned with the regulation of the transport of dangerous goods. They do not apply to the bulk transport of dangerous goods in sea-going or inland navigation bulk carriers or tank-vessels, which is subject to special international or national regulations.

The Recommendations concerning the transport of dangerous goods and wastes are presented in the form of "Model Regulations on the Transport of Dangerous Goods", which are presented as annexes to the Model itself (UN, 2009b). The Model Regulations have the aim of presenting a basic scheme of provisions that will allow a uniform development of the national and international regulations that govern the various modes of transport. However, they remain flexible enough to accommodate any special requirements that might have to be met. It is expected that governments, intergovernmental organizations and other international organizations, when revising or developing regulations for which they are responsible, will conform to the principles laid down in these Model Regulations, thus contributing to worldwide harmonization in this field. Furthermore, the new structure, format and content should be followed to the greatest extent possible in order to create a more user-friendly approach, to facilitate the study of enforcement bodies and to reduce the administrative burden. Although only a recommendation, the Model Regulations have been drafted in the mandatory sense (i.e., the word "shall" is employed throughout the text rather than "should") in order to facilitate direct use of the Model Regulations as a basis for national and international transport regulations.

Amongst other aspects, the Model Regulations cover principles of classification and the definition of classes, listing of the principal dangerous goods, general packing requirements, testing procedures, marking, labelling or placarding and transport documents. There are, in addition, special requirements related to particular classes of goods or wastes.

The UN Sub-Committee of Experts on the Transport of Dangerous Goods (UNSCETDG) devised a system of nine classes for substances. The system of classes was established bearing in mind the type of containment to be used, the chemical and physical characteristics of the substances and response procedures that would be most appropriate in the event of an accidental release.

These 9 hazard classes have been established internationally by a United Nations (UN) committee to ensure that all modes of transport (road, rail, air and sea) classify dangerous goods in the same way (Table 1). Consequently, in the UN Model Regulations each substance has a name (called a Proper Shipping Name) and a four digit UN number and, according to its chemical and physical characteristics, is assigned to a class and a packing group. It should be noted that the numerical order of the classes does not indicate the degree of danger.

For purposes of selecting the appropriate packaging for dangerous goods, substances are further divided into packing groups (although some classes do not have packing groups, i.e., Class 2, Division 6.2 and Class 7) in accordance with the degree of danger they present:

Packing Group I: High danger

Packing Group II: Medium danger

Packing Group III: Low danger 
Many of the goods included in Classes 1-9 are deemed dangerous to the environment.

Dangerous waste (other than radioactive wastes) should be transported considering the requirements of the appropriate class, considering their hazards and the criteria presented in the Model Regulations. Wastes which do not qualify for classification for classes 1 to 9 , but are covered by the Basel Convention on the Control of Transboundary Movements of hazardous Wastes and their Disposal, may be carried under UN Nos. 3077 (ENVIRONMENTALLY HAZARDOUS SUBSTANCE, SOLID, N.O.S.-not otherwise specified) or 3082 (ENVIRONMENTALLY HAZARDOUS SUBSTANCE, LIQUID, N.O.S.). These entries may also be used for substances, by the competent authorities of the country of origin, transit or destination, which do not meet the criteria for an environmentally hazardous substance.

For wastes which are being transported for disposal, or for processing for disposal, the Proper Shipping Name should be preceded by the word "WASTE", unless this is already a part of the proper shipping name.

Additional labeling or marking is not always specified, other than for UN Nos. 3077 and 3082, except for transport by sea. Criteria for substances and mixtures considered dangerous for the aquatic environment are given in Chapter 2.9 of the Model Regulations.

\subsection{UNECE Agreements for the Transport of Dangerous Goods by Road, Rail and Inland Waterways}

ECOSOC set up in 1947 by the UN Economic Commission for Europe (UNECE). It is one of five regional UN commissions. The others are the Economic Commissions for Africa (ECA), for Asia and the Pacific (ESCAP), for Latin America and the Caribbean (ECLAC) and for Western Asia (ESCWA).

As a multilateral platform, UNECE brings together 56 countries located in the European Union, non-EU Western and Eastern Europe, South-East Europe and the Commonwealth of Independent States (CIS) and North America. All these countries dialogue and cooperate under the aegis of UNECE on economic and sectoral issues. UNECE focuses on the UN global mandates in the economic field, in cooperation with other global players and key stakeholders, notably the business community.

One of the areas of UNECE's study concerns the international Transport of Dangerous Goods (TDG) by road, rail and inland waterways. UNECE administers regional agreements, as far as the transport of dangerous goods is concerned.
Table 1. List of the 9 hazard classes for all modes of transport.

\begin{tabular}{|c|c|}
\hline Class 1 & Explosives \\
\hline Class $2(*)$ & Gases \\
\hline Class 3 & Flammable liquids \\
\hline Class 4 & Flammable solids \\
\hline Class 5 & Oxidizing substances and organic peroxides \\
\hline Class 6 & Toxic and infectious substances \\
\hline Class $7(*)$ & Radioactive material \\
\hline Class 8 & Corrosive substances \\
\hline Class 9 & Miscellaneous dangerous substances and articles \\
\hline
\end{tabular}

\subsection{Transport by Road (ADR)}

The European Agreement concerning the International Carriage of Dangerous Goods by Road (ADR) was drawn up in Geneva on 30 September 1957, under the auspices of the United Nations Economic Commission for Europe and it entered into force on 29 January 1968. The Agreement itself was amended by Protocol amending article 14 (3) which has drawn up in New York on 21 August 1975 and which entered into force on 19 April 1985. Article 2 of the Agreement is it's the key article, which states that, apart from some excessively dangerous goods, other dangerous goods may be carried internationally in road vehicles subject to compliance with:

- The conditions laid down in Annex A for the goods in question, in particular as regards their packaging and labeling

- The conditions laid down in Annex B, in particular as regards the construction, equipment and operation of the vehicle carrying the goods in question

Annexes A and B have been regularly amended and updated since the entry into force of ADR. Following the amendments for entry into force on 1 January 2011, a revised consolidated version was published as document ECE/TRANS/215, Vol. I and II (“ADR 2011”) (UNECE, 2011). The ADR has been adopted in 46 countries.

\subsection{Transport by Rail (RID)}

The first International Convention concerning the Carriage of Goods by Rail dates back to the year 1890 . This Convention created an Administrative Union according to the international law rules of that time. The Intergovernmental Organisation for International Carriage by Rail (OTIF) was set up (the abbreviations are derived from the original French version of the titles) with the entry into force, on 1 May 1985, of the Convention concerning International Carriage by Rail of 9 May 1980 (COTIF).

Further significant modification of COTIF was brought about by the Vilnius Protocol of 3 June 1999 (1999 Protocol), which entered into force on 1 July 2006. 
IOICR (2011): Regulations concerning the International Carriage of Dangerous Goods by Rail (RID 2011) entered into force on 1 January 2011.

It is necessary to point out that the uniform rules currently applicable to international carriage by rail are contained in the COTIF: Uniform Rules concerning the Contract of International Carriage of Goods by Rail (CIM) and Uniform Rules concerning the Technical Admission of Railway Material used in International Traffic (ATMF).

At present, there are 46 Member States of OTIF (in Europe/the Middle East and North Africa) and one State is an Associate Member (Jordan).

\subsection{Transport by Inland Waterways (ADN)}

The European Agreement concerning the International Carriage of Dangerous Goods by Inland Waterways (ADN) was drawn up in Geneva on 26 May 2000 on the occasion of a Diplomatic Conference held under the joint auspices of the UNECE and the Central Commission for the Navigation of the Rhine (CCNR). It entered into force on 29 February 2008 (UNECE, 2006).

ADN consists of a main legal text (the Agreement itself) and annexed Regulations.

The Regulations annexed to the ADN contain provisions concerning dangerous substances and articles, provisions concerning their carriage in packages and in bulk on board inland navigation vessels or tank vessels, as well as provisions concerning the construction and operation of such vessels. They also address requirements and procedures for inspections, the issue of certificates of approval, recognition of classification societies, monitoring and training and examination of experts.

It should be noted that, according to Directive $2008 / 68 / E C$ on the inland transport of dangerous goods, Member States of the European Union, should, with the exclusion of the derogation provided for in Article 1, paragraph 3 of the Directive, apply these annexed Regulations as well as Article 3 (f) and (h) and Article 8, paragraphs 1 and 3 of the Agreement to the transport of dangerous goods by inland waterways from 1 July 2009 and at the latest by 30 June 2011 .

\subsection{Transport by Sea}

Today the International Maritime Organization (IMO) is a specialized United Nations agency. In 1948, an international conference in Geneva adopted a convention formally establishing IMO (the original name was the Inter-Governmental Maritime Consultative Organization, or IMCO, but the name was changed in 1982 to IMO). The IMO Convention entered into force in 1958.

IMO's first task was to adopt a new version of the International Convention for the Safety of Life at Sea
(SOLAS), the most important of all treaties dealing with maritime safety (IMO, 2009). This was achieved in 1960 and IMO then turned its attention to such matters as the facilitation of international maritime traffic, load lines and the carriage of dangerous goods, while the system of measuring the tonnage of ships was revised.

After the Torrey Canyon disaster in 1967, in which 120,000 tonnes of oil was spilled, IMO introduced a series of measures designed to prevent tanker accidents and to minimize their consequences. The most important of all these measures was the International Convention for the Prevention of Pollution from Ships, (MARPOL 73/78) (IMO, 1973). It covers not only accidental and operational oil pollution, but also pollution by chemicals, goods in packaged form, sewage, garbage and air pollution.

The International Convention for the Safety of Life at Sea, 1974 (SOLAS), as amended, contains the mandatory provisions governing the carriage of dangerous goods in packaged form or in solid form in bulk in chapter VII. The carriage of dangerous goods is prohibited, except in accordance with the relevant provisions of chapter VII and of the International Maritime Dangerous Goods (IMDG) Code.

Regulation II- $2 / 19$ of the SOLAS Convention, as amended, specifies the special requirements for a ship that intends to carry dangerous goods, the keel of which was laid, or which was at a similar stage of construction, on or after 1 July 2002.

The International Convention for the Prevention of Pollution from Ships, 1973, as modified in 1978, deals with various aspects of prevention of marine pollution and contains the mandatory provisions for the prevention of pollution by harmful substances carried by sea in packaged form in Annex III. Regulation 1(2) prohibits the carriage of harmful substances in ships except in accordance with the provisions of Annex III and of the IMDG Code.

In accordance with the Provisions concerning Reports on Incidents Involving Harmful Substances (Protocol I to MARPOL), incidents involving the loss of such substances from ships should be reported by the master or any other person in charge of the ship. Each substance defined as harmful to the marine environment is identified as a marine pollutant in column 4 of the Dangerous Goods List and in the Index of the IMDG Code with the letter P.

The IMDG Code that was adopted by resolution A.716(17) and amended by Amendments 27-30, was recommended to Governments for adoption or for use as the basis for national regulations in pursuance of their obligations under regulation VII/1.4 of the 1974 SOLAS Convention, as amended and regulation 1(3) of Annex 
III of MARPOL. The IMDG Code, as amended, attained mandatory status on 1 January 2004, under the umbrella of SOLAS, 1974; however, some parts of the Code continue to be recommendatory. Observance of the Code lead to a harmonization of the practices and procedures followed in the carriage of dangerous goods by sea and ensures compliance with the mandatory provisions of the SOLAS Convention and of Annex III of MARPOL.

In the following, reference is made to the IMDG Code 2010 Edition which incorporates Amendment 3510 of IMO (IMO, 2008).

\subsection{Transport by Air}

Convention on International Civil Aviation (also known as the Chicago Convention), was signed on 7 December 1944 by 52 States. The Provisional International Civil Aviation Organization (PICAO) was established, pending ratification of the Convention by 26 States. It functioned from 6 June 1945 until 4 April 1947. The 26th ratification was received by 5 March 1947. ICAO came into being on 4 April 1947. In October of the same year, ICAO became a specialized United Nations agency linked to Economic and Social Council (ECOSOC). The current edition of the Chicago Convention, the ninth, was published ad Doc $7300 / 9$ in 2006 (ECOSOC, 2006).

ICAO was created to promote the safe and orderly development of international civil aviation throughout the world. It sets standards and regulations that are necessary for aviation safety, security, efficiency and regularity, as well as for aviation environmental protection. The Organization serves as the forum for cooperation in all fields of civil aviation among its 191 Member States.

The Chicago Convention also deals with the Safe Transport of Dangerous Goods by Air. In general, it sets down broad principles, but one of the Standards requires that dangerous goods are carried in accordance with the Technical Instructions for the Safe Transport of Dangerous Goods by Air-Doc 9284 (the "Technical Instructions") (ICAO, 2007). States are required, by Annex 18, to carry out inspection and enforcement procedures to ensure that dangerous goods are being carried in compliance with the requirements.

The Technical Instructions contain a very comprehensive set of requirements; among other things they provide for the classification of dangerous goods and have a list of these goods. The list identifies those goods which are: (a) forbidden under any circumstances; (b) forbidden on both passenger and cargo aircraft in normal circumstances, but could be carried in exceptional circumstances subject to exemption by the States concerned; (c) forbidden on passenger aircraft, but permitted on cargo aircraft in normal circumstances; and (d) permitted on both passenger and cargo aircraft in normal circumstances. The Technical Instructions require that all dangerous goods be packaged and, in general, restrict the quantity per package, according to the degree of hazard and the type of aircraft (i.e., passenger or cargo) that is going to be used. There is generally no restriction on the number of packages per aircraft. The Instructions also give the packing methods that should be used and the packagings permitted, together with the specifications for those packagings and the stringent testing regime they must successfully complete before they can be used. There are requirements for the markings and labels for packages and the documentation for consignments.

The International Air Transport Association (IATA) is an international trade body, that was created over 60 years ago by a group of airlines. Today, IATA represents some 240 airlines and comprises $84 \%$ of the total air traffic. The organization also represents, leads and serves the airline industry in general.

The IATA "Dangerous Goods Center of Expertise" works closely with governments, ICAO and other national authorities, in the development of transport regulations of dangerous goods by air.

The IATA Dangerous Goods Regulations (DGR 53rd Edn.) came into force on 1 January 2012 (IATA, 2010).

It covers every facet of international shipping regulations, including a comprehensive Dangerous Goods list which gives details on Proper Shipping Names and labeling requirements, packing requirements, training guidelines and up-to-date information on shipping forms.

\subsection{Multimodal Transport Documentation}

In order to ensure the easy multimodal transport of dangerous goods, the structure and contents of the various mode-specific provisions ADR/ADN/RID/IMDG are now for the most part aligned with the UN Recommendations on the Transport of Dangerous Goods (UN Model Regulations). At present, these UN Model Regulations are revised every two years. The result of this is that the mode-specific regulations are also revised in the same cycle.

Parts 5 of the ADR, ADN, RID and IMDG Code, entitled "Consignement Procedures", all set forth the provisions for the consignement of dangerous goods relative to the authorization of consignments and advance notifications, marking, labeling, documentation (by manual, Electronic Data Processing (EDP) or Electronic Data Interchange (EDI) techniques) and placarding. 
The information applicable to the dangerous goods should accompany the dangerous goods to their final destination. This information may be on the dangerous goods transport document or may be on another document. This information should be given to the consignee when the dangerous goods are delivered.

The purpose of indicating the Proper Shipping Name (see 3.1.2.1 and 3.1.2.2) and the UN Number of a substance, material or article offered for transport and, in the case of a marine pollutant, of the addition of "marine pollutant" on the documentation accompanying the consignment and of marking the Proper Shipping Name in accordance with 5.2.1 on the package, including Intermediate Bulk Containers (IBCs) containing the goods, is to ensure that the substance, material or article can be readily identified during transport. This ready identification is particularly important in the case of an accident involving these goods, in order to determine what emergency procedures are necessary to deal with the situation and, in the case of marine pollutants, for the master to comply with the MARPOL 73/78 requirements of Protocol I.

\subsection{Connection between the Classifications and the Notification and Movement Document for Hazardous Waste}

The connections between the classifications to which reference is here made and the notification and movement document for hazardous waste, can be found in boxes 4-8 and in box 14 :

Boxes 4-6: For single or multiple movements, give the number of shipments in box 4 and the intended date(s) of the single shipment or of the first and last shipments in box 6 . In box 5 , give the weight in $\mathrm{Mg}$ (i.e.,: megagram or $1000 \mathrm{~kg}$ or 1 tonne) or volume in $\mathrm{m}^{3}$ (i.e.,: 1000 litres) of the waste shipment using the metric system. Other units of the metric system, e.g., kg or litres, are also acceptable; in this case, the unit should be indicated in the form and the unit in the form should be crossed out. Some countries may require the weight to be quoted. For multiple shipments, the total quantity shipped must not exceed the quantity declared in box 5 . The intended period of time for movements in box 6 may not exceed the period of one year, with the exception in the OECD Decision of multiple shipments to pre-consented recovery facilities (see third bullet under box 3) for which the intended period of time may not exceed three years. In the case of multiple shipments, the Basel Convention requires the expected dates or the expected frequency and the estimated quantity of each shipment to be quoted in boxes 5 and 6 or attached in an annex. In the case where a competent authority issues a written consent to the movement and the validity period of that consent in box 20 differs from the period indicated in box 6 , the decision of the competent authority overrules the information in box 6 .

Box 7: Use the codes provided in the list of abbreviations and codes following the form of the Notification Document for the type(s) of packaging. If special handling precautions are required, e.g., producer's handling instructions for employees, health and safety information, including dealing with spillage, Transport Emergency Cards, tick the appropriate box and attach the information in an annex.

Box 8: Provide all the necessary information concerning the carrier(s) involved in the shipment: registration number (where applicable), full name, address (including the name of the country), telephone/fax numbers (including the country code) and e-mail address as well as the name of a contact person responsible for the shipment. If more than one carrier is involved, append a complete list to the Notification Document giving the required information for each carrier. Where the transport is organised by a forwarding agent, the details on the forwarding agent should be given in box 8 and the respective information on the actual carriers should be provided in an annex. For the mean(s) of transport, use the abbreviations provided in the list of abbreviations and codes in the Notification Document.

Box 14: The ONU number, the ONU documentation and the hazard characteristic $\mathrm{H}$ can be found in this block.

\section{RESULTS}

\subsection{National/Regional Regulatory Systems Vs GHS}

Many countries already have regulatory systems for many types of GHS requirements. These systems may be similar in content and approach, but their differences are significant enough to require multiple classifications, labels and safety data sheets for the same product when marketed in different countries, or even in the same country when parts of the life cycle are covered by 
different regulatory authorities. This leads to inconsistent protection for those potentially exposed to the chemicals, as well as creating extensive regulatory burdens on the companies that produce chemicals. For example, in the United States, there are requirements for the classification and labeling of chemicals for the Consumer Product Safety Commission, the Department of Transportation, the Environmental Protection Agency and the Occupational Safety and Health Administration.

It can be observed how complex it is to comply with all domestic and global regulations by comparing a few hazards. For example, in the case of acute oral toxicity (LD50), although most existing systems cover acute toxicity, it can be seen that what is considered hazardous varies considerably. These differences allow the same product to be hazardous in one country/system and not in another. At the very least, the same product has different labels and SDSs. Flammable liquid is another hazard that is covered by most existing systems. The coverage varies between existing systems within various agencies within the U.S. and globally. This means that the same product can be non-hazardous or hazardous with different labels/SDSs.

The GHS Document establishes agreed hazard classification and communication provisions with explanatory information on how to apply the system. The elements in the GHS supply a mechanism to meet the basic requirement of any hazard communication system, which is to decide whether the produced and/or supplied chemical product is hazardous and to prepare a label and/or SDSs as appropriate. Regulatory authorities in countries that adopt the GHS will thus take the agreed criteria and provisions and implement them through their own regulatory processes and procedures rather than simply incorporating the text of the GHS into their national requirements.

The European Union (EU) has modernised European chemical legislation and established REACH (Regulation (EC) No 1907/2006), an integrated system for the registration, evaluation, authorisation and restriction of chemicals. A European Chemical Agency is also being set up to deal with the day-to-day management of REACH requirements. This Regulation amends Directive 67/548/EEC on chemical substances and Directive 1999/45/EC on mixtures and repeals them, with effect from 1 June 2015. The EU will adapt its system in order to classify chemical substances and mixtures to the UN GHS. The rules introduced by the GHS are integrated in the EU Regulation, which will gradually replace current legislation on the classification, labeling and packaging of chemical substances and mixtures.

\subsection{Particular Exemptions/Limited Quantities}

Attention should be paid to the "limited quantity" theme of hazardous substances and waste for all types of transport. Examining this point (par. 1-10.4) in detail, it can be observed that the quantities for which the "General Provisions" (par. 1.10.1) and the "Security training" outlined in Chapter 10 (which concerns the "measures or precautions to be taken to minimize theft or misuse of hazardous goods that may endanger persons, property or the environment") are necessary, only concern some materials in class 1 (explosives); moreover, the safety plan is only necessary for "High consequence dangerous goods", that is, "those which have the potential for misuse in a terroristic incident and which may, as a result, produce serious consequences, such as mass casualties or mass destruction".

\subsection{Uncertainties in the RID}

Member States of the OTIF have, in accordance with the first sentence of Article $42 \S 1$ of COTIF 1999, the opportunity to make declarations not to apply, in their entirety, certain Appendices to the Convention. A special term-Contracting State-which means a Member State that has not made a declaration not to apply the rule concerned was introduced into Appendices F (APTU) and G (ATMF). The term "RID Contracting State" was introduced into the RID 2011 and the term "Member States" was replaced with "RID Contracting States". For instance, the Russian Federation acceded to OTIF with effect from 1 February 2010 and made a declaration not to apply the Rule Indicated (RID).

An essential problem of the RID system depended, in principle, on the scope of application of the CIM Uniform Rules. From this, there were three important formal restrictions:

- RID applied only to international carriage

- It applied only to carriage on lines included in the CIM list. Uniform Rules concerning the Contract of International Carriage of Goods by Rail (CIM)

- Carriage had to be performed on the basis of a CIM contract of carriage covered by a CIM consignment note

Safety regulations that have the purpose of protecting persons, the environment and goods should, however, be applicable, irrespective of such formal restrictions.

Furthermore, substantial difficulties have arisen from the legal structure of RID, in the context of the carriage of empty tank-wagons, empty tank containers as well as empty wagons and empty small containers for bulk goods, those uncleaned wagons and containers, belonging to the railway, that have contained dangerous goods. Such carriage was performed by the railway 
without the conclusion of a CIM contract of carriage and was thus not subject to RID. This problem was resolved transitionally by an additional uniform rule of railways (Additional Uniform Rule No. 2, of railways, to Article 28 CIM 1980), a provision which imposes certain obligations on the consignee of the preceding loaded carriage in order to guarantee safety in the subsequent carriage without load. The CIM contract of carriage now commences with the acceptance of the goods for transport with the consignment note and ends with the delivery of the goods. The loading and unloading activities are frequently performed outside this timeframe, particularly as far as the carriage of wagon loads is concerned. The typical dangers associated with the carriage of dangerous goods are thus not limited by the duration of the contract of carriage. The obligations which now ensue from RID no longer apply solely to the parties to the contract of carriage (consignor, consignee and carrier). The stipulations relating to gas return (gas compensation pipe), which create obligations for the filler and the unloader, even when the latter are not directly involved as a consignor or consignee in the contract of carriage, are a concrete example of these obligations.

The term "international" has not yet been defined. However, it is necessary for the carriage to have been performed on the territory of at least two Member States. Moreover, the applicability of RID does not depend on the fact of the carriage being subject or not subject to CIM Uniform Rules (see Nos. 3-5 of the General Points).

In addition to the carriage itself, the field of application also includes all the activities provided for by the Annex and in particular the loading and unloading operations of dangerous goods. In Part 1 of the Annex, General Provisions, the term carriage is defined substantively and independently of the contract of carriage, namely, as the change in place of dangerous goods, including stops made necessary by transport conditions and including any period spent by the dangerous goods in wagons, tanks and containers made necessary by traffic conditions before, during and after the change in place. The term "carriage" also covers the intermediate temporary storage of dangerous goods in order to change the mode or means of transport (transhipment).

\subsection{Uncertainties in the IMDG Code}

The IMDG Code, which sets out a detailed description of the requirements applicable to each individual substance, material or article, has undergone many changes, in both layout and content, in order to keep pace with the expansion and progress of industry. IMO's Maritime Safety Committee (MSC) is authorized by the Organization's Assembly to adopt amendments to the Code, thus enabling IMO to respond promptly to developments in transport.
The MSC, at its eighty-seventh session agreed that, in order to facilitate the multimodal transport of dangerous goods, the provisions of the IMDG Code, 2010, may be applied from 1 January 2011 on a voluntary basis, pending their official entry into force on 1 January 2012, without any transitional period. This is described in resolution MSC.294 (87) and the Preamble to this Code. It should be emphasized that, in the context of the language of the Code, the words "shall", "should" and "may", when used in the Code, mean that the relevant provisions are "mandatory", "recommendatory" and "optional", respectively.

\subsection{The Multimodal Transport of PCBs}

In order to fully understand this study case, it is necessary to read what has been written in the companion study in relation to the transboundary movement of hazardous material. As far as the multimodal transport of PCBs is concerned, reference should be made the UN Recommendations on the Transport of Dangerous Goods, Models Regulations and apply the IMDG Code, ICAO Technical Instructions, ADR, RID, ADN. For road, rail and inland waterways transport it may be necessary to take into account national regulations.

The classification of PCBs for their transport must begin with an identification of the hazards they have:

- No physical hazard (explosivity, reactivity, flammability)

- No acute health hazard (toxicity, corrosivity) that could present a problem for transport

- Hazard to the environment

PCBs, PCTs, polyhalogenated byphenils, terfenyls and mixtures containing these substances, as well as apparatus such as transformers, condensers and apparatus containing these substances or mixtures are "Substances and apparatus which, in the event of fire, may form dioxins: Classification Code M2". Mixtures with a PCB or PCT content of no more than $50 \mathrm{mg} \mathrm{kg}^{-1}$ are not subject to the provisions of the Codes.

Only if the concentration is $\geq 50 \mathrm{mg} \mathrm{kg}{ }^{-1}$, do they constitutes a "Hazard to the environment". The UN Class transport for PCBs is 9: "Miscellaneous dangerous goods". The Packing Group is II (Medium danger).

The complete entry is:
UN 2315 Polychlorinated biphenyls, liquid
UN 3432 Polychlorinated biphenyls, solid
UN 3151 Polyhalogenated biphenyls, liquid (or polyhalogenated terphenyls, liquid)
UN 3152 Polyhalogenated biphenyls, solid, or polyhalogenated terphenyls, liquid 
It should be noted that uncleaned empty container vessels for apparatus such as transformers, condensers and hydraulic apparatus containing substances assigned to UN Nos. 2315, 3432, 3151 or 31522 should not accepted for carriage.

General provisions for the packing of dangerous goods in packagings including IBCs are provided in the Part 4 of the UN Recommediations. Particular attention is necessary for good quality packagings which should be strong enough to withstand the shocks and loadings normally encountered during carriage, including trans shipment between transport units and between transport units and warehouses. Packagings, including IBCs, should be constructed and closed to prevent any loss of contents when prepared for transport which might be caused under normal conditions of transport, by vibration, or by changes in temperature, humidity or pressure (resulting from altitude, for example).

A list instruction is given for packagings (P001liquids; P002-solids) in Annex 1 of the UN Recommendation. In packing instruction 906, the following packages are authorized, provided the general provisions are met:

- For liquids and solids containing or contaminated with PCBs or polyhalogenated byphenyls or terphenils: packagings in accordance with P001 or P002, as appropriate

- For tranformers and condensers and other devices: leakproof packagings which are capable of containing, in addition to the devices, at least 1.25 times the volume of liquid PCBs or polyhalogenated byphenyls or terphenils present in them. There should be sufficient adsorbent material in the packagings to adsorb at least 1.1 times the volume of liquid which is contained in the devices. In general, tranformers and condensers should be carried in leakproof metal packagings which are capable of holding, in addition to the tranformers and condensers, at least 1.25 times the volume of liquid present in them

In spite of these regulations, liquid and solids not packaged in accordance with P001 and P002 and unpackaged tranformers and condensers may be carried in cargo transport units fitted with a leak proof metal tray to a height of at least $800 \mathrm{~mm}$, containing sufficient inert absorbent material to adsorb at least 1.1 times the volume of any free liquid. As an additional requirement, adequate provisions should be taken to seal the tranformers and condensers to prevent leakage during normal carriage conditions.

Packing instructions concerning the use of IBCs are given in Annex 2 (IBC02-liquids; IBC08/B4-solids) of the UN Recommedations.

Packagings and IBCs have to be constructed and tested to the packing group II performance standard and certified in accordance with the UN Model Regulations.

\section{DISCUSSION}

\subsection{Difficulties in the Judicial Models}

In the study of the technical-judicial model of the transboundary movement of hazardous waste Carosso (2001b) raised the problem of the difficulties inherent to the definition of waste and of product. Not only has this difficulty still not been resolved, but has become amplified in the technical-judicial model of the international transport of hazardous goods and waste. The problem is related to the lack of scientific knowledge concerning some products or, from a more general point of view, to scientific developments, as it is possible for new products to appear on the market without appropriate tests on the danger of new substances having been performed. This can also cause problems because the hazardous nature of certain products only appears after a certain period of time from when the object appears on the market. The danger exists along the transport chain, but also in the handling, movement, loading and unloading phases and it puts the safety of the workers and third parties at jeopardy. The incorrect qualification of a product or waste makes this danger even greater because of the vicinity of products or waste that should be subjected to completely separate operations. The problem of the so-called "limited quantity", which leads to exemptions from determined obligations, is often faced in a non-conservative manner and so much so that the exemption is often adopted and the procedures that are necessary are absent.

\subsection{Difficulties in the Controls}

As already pointed out, the different interpretations of "waste" and "product", even by the authorities and enforcement agencies of the exporting and importing counties, leave the main problem unresolved and make the controls an almost purely bureaucratic procedure limited to the documents that accompany the transported material. Furthermore, it is not possible to carry out areawide or permanent inspections, since waste (products) inspections are very expensive and must be well organized and prepared. Many countries are often not equipped with the special know-how, infrastructures and specially educated staff and often lack money to organise and operate inspections in their countries. Finally, the problems are made worse by the widespread allocation of tasks and competences, which sometimes even takes place over various regions.

\subsection{Difficulties that have Emerged in the Study Case of PCBs}

The lack of solution to the basic problem of "what is waste and what are goods" has clearly emerged in the study of PCBs. In this study, the authors have limited 
themselves to reporting the sequence of the classification, labeling and packaging activities. The problem would seem, in this context, to be concentrated on bureaucratic formalities, without going to the source of the problem. For this reason, the readers should refer to the companion study in which the problems that arise when PCBs are considered as products or as waste are examined.

\section{CONCLUSION}

\subsection{What the Decision Makers Can Do?}

The attention of the decision makers should be concentrated on two fundamental aspects. The first concerns the fundamental theme of the difference between goods and waste which, being unresolved, makes many parts of the two models weak with amplification effects of the problem on the second model. The second aspect regards the controls that should be conducted. Examining the situation of PCBs, it has clearly emerged that there is a clear lack of solution to the basic problem "what is waste and what are goods". If this problem is not resolved at a general and a particular level and all the involved parties are not involved and if a unique and unambiguous definition of waste is not decided upon, the door will continue to remain open to organized crime. It should also be pointed out that the technological development and the refinement of industrial processes and products-together with the different degrees of social and economic development of the various countries-make the passage from product to waste quicker, in a certain sense. As is commonly believed and regardless of any other considerations, the more a society develops, the more it tends to free itself of products which consequently end up as waste.

The difficult goal of an improvement in the technical-judicial model can be obtained through the joint study of experts from both a judicial background and from the technical field. The two forms of competence should be placed side by side. The experts should be chosen from among high profile and super partes technical and judicial experts who are recognized as such at an international level: these experts should answer for their actions to the international organizations since a similar activity, in order to be efficacious, should be conducted at the UN level.

\section{REFERENCES}

Blengini, G.A., M. Fantoni, M. Busto, G. Genon and M.C. Zanetti, 2012. Participatory approach, acceptability and transparency of waste management LCAs: Case studies of Torino and Cuneo. Waste Manage. PMID: 22583569

Carosso, A., 2010. Urban Cultures Of/In the United States: Interdisciplinary Perspectives, Peter Lang, USA., ISBN-10: 3034300824, pp: 183.

Carosso, G., 2001a. Consulente per la sicurezza; il trasporto su strada di rifiuti pericolosi [prima parte]. RivistaAmbiente, 2: 133-139.
Carosso, G., 2001b. Consulente per la sicurezza; il trasporto su strada di rifiuti pericolosi [seconda parte]. RivistaAmbiente, 3: 270-274.

ECOSOC, 2006. Chicago convention. ECOSOC.

Fiore, S., B. Ruffino, M.C. Zanetti, 2012. Automobile Shredder Residues in Italy: Characterization and valorization opportunities. Waste Manage., 32: 1548-1559. DOI: 10.1016/j.wasman.2012.03.026

Fiore, S., M. Zanetti and B. Ruffino, 2008. Waste characterization in steel casting and recycling opportunities in Europe. Am. J. Applied Sci., 5: 512518. DOI: 10.3844/ajassp.2008.512.518

IATA, 2010. IATA Dangerous Goods Regulations. 51th Edn., International Air Transport Association, Montreal, ISBN-10: 9292332171, pp: 1027.

ICAO, 2007. Technical Instructions for the Safe Transport of Dangerous Goods by Air: Supplement. 1st Edn., ICAO, Quebec, ISBN-10: 9291948233.

IMO, 1973. International convention for the prevention of pollution from ships (MARPOL). International Maritime Organization.

IMO, 2008. IMDG code: International maritime dangerous goods code: Incorporating amendment 33-06. 1st Edn., International Maritime Organization, ISBN-10: 9280142151, pp: 383.

IMO, 2009. International Convention for the Safety of Life at Sea (SOLAS)-consolidated. 5th Edn., International Maritime Organization, London, ISBN-10: 978928015055 , pp: 433.

IOICR, 2011. Regulations concerning the International Carriage of Dangerous Goods by Rail (RID). OTIF.

Mathur, A. and D. Siddharth, 2009. Multilateral environmental agreements versus world trade organization system: A comprehensive study. Am. J. Econ. Bus. Admin., 1: 219-224. DOI: 10.3844/ajebasp.2009.219.224

Oreste, P. and M. Castellano, 2012. An applied study on the debris recycling in tunnelling. Am. J. Environ. Sci. 8: 179-184, DOI: 10.3844/ajessp.2012.179.184

Sumit, K.J., 2009. Development or environment. Am. J. Econ. Bus. Admin., 1: 257-262, 2009. DOI: 10.3844/ajebasp.2009.257.262

UN, 2009a. Globally Harmonized System of Classification and Labelling of Chemicals (GHS). 3rd Edn., United Nations Publications, New York, ISBN-10: 9211170060 , pp: 559.

UN, 2009b. Recommendations on the Transport of Dangerous Goods: Model Regulations. 16th Edn., United Nations Publications, New York, ISBN-10: 9211391369, pp: 808.

UNECE, 2006. European Agreement Concerning the International Carriage of Dangerous Goods by Inland Waterways (ADN). 1st Edn., United Nations Publications, New York, ISBN-10: 9211391164 , pp: 957.

UNECE, 2011. ADR 2011 (European Agreement Concerning the International Carriage of Dangerous Goods by Road) United Nations. 